\title{
Dermatomiositis luego de implante mamario de silicona
}

\section{Ricardo Vicente Juárez}

Hospital Señor del Milagro, Salta

\section{Introducción}

El primer caso de enfermedad reumática asociada a implante mamario de silicona fue reportado en 1982. Desde esa fecha, los estudios epidemiológicos no han demostrado una asociación estadística entre estas dos entidades. La exposición a la silicona se ha asociado a la patogénesis de enfermedades autoinmunes. Un nuevo síndrome fue descripto y llamado "ASIA" (auto-inflammatory Syndrom Induced by Adyuvant) por Agmon-Levin y Shoeneld $\mathrm{Y}^{1}$. Este síndrome abarca síntomas que aparecen luego de una exposición crónica a silicona, tetrametilpentadecano, pristaine, aluminio y otros adyuvantes ${ }^{2}$. Este caso describe a una mujer que desarrolla dermatomiositis luego de seis meses de un implante mamario de silicona con anticuerpos antiosfolipídicos.

\section{Caso}

Mujer de 46 años residente en la localidad de Cerrillos Salta.

Consulta por dificultad progresiva para levantar objetos y caminar 100 metros, asociado a la presencia de lesiones de Gottron en codos y superficie de las articulaciones metacarpofalángicas en forma bilateral de seis meses de evolución con necrosis distal de la tercera falange de la mano izquierda 7 días previo a la consulta.

Cinco meses antes requiere ser internada por presentar artralgias y mialgias que se interpretan vinculadas a cuadro inicial. Se realiza diagnóstico presuntivo de Dermatomiositis. Durante su internación se le administró dexametasona $8 \mathrm{mg}$ cada 8 horas. Los estudios de laboratorio se muestran en Tabla 1 ( 5 meses previos).

Presenta antecedentes de insuficiencia mitral con controles periódicos cardiológicos, tabaquismo 20 pack años, tratamiento completo por tuberculosis pulmonar.
Como antecedentes quirúrgicos siete meses antes del inicio de su cuadro se realizó implantes mamarios de siliconas; otras intervenciones fueron dos cesáreas, várices por insuficiencia venosa y apendicectomía. Antecedentes gineco-obstétricos: dos gestas dos cesáreas. Estaba medicada con atenolol $50 \mathrm{mg}$ día, metilprednisona $30 \mathrm{mg}$ día. No refería alergias, no consumía alcohol ni drogas ilícitas. No tenía antecedentes familiares de enfermedades reumáticas. Al examen físico su temperatura axilar era de $36^{\circ}$, presión arterial de 160/90, su frecuencia cardíaca de 72 latidos por minuto y su frecuencia respiratoria de 22 por minuto, fascies cushigoide, soplo 2/6 sistólico en foco mitral. Se realizan estudios complementarios (Tabla 1). En el laboratorio se evidencia elevación de CPK 246 U/L(VN 40-167 U/L) y FAN 1/80 moteado. La radiografía de tórax era normal excepto por la presencia de los implantes mamarios. El electrocardiograma presenta ritmo sinusal QRS $30^{\circ}$ qs V1 a V3 y elevación del segmento ST.

La paciente es internada para realizar pulsos de metilprednisona de $1 \mathrm{~g}$ por tres días y ciclofosfamida $1 \mathrm{~g}$, con diagnóstico presuntivo de Vasculitis, Síndrome Antifosfolipídico se le indica además enoxaparina $40 \mathrm{mg}$ día, se cambia el tratamiento con atenolol por amlodipina.

La paciente viaja a la Ciudad de Buenos Aires para realizar una interconsulta a un centro de alta complejidad; en esa oportunidad se duplica la dosis de enoxaparina y se le agrega sildenafil, en el laboratorio presenta CPK normal, aldolasa 8,7 UI/l (vn de 0 a 7,6) y Anticoagulante lúpico positivo.

De regreso a la ciudad de origen, a pesar del tratamiento instituido, la paciente evoluciona en forma tórpida. Presenta deterioro del sensorio requiriendo asistencia respiratoria mecánica. Se descartan intercurrencias infecciosas, se le realiza nuevo pulso de metilprednisona y segunda infusión de ciclofosfamida. La condición de la

\section{Correspondencia}




\begin{tabular}{|c|c|c|c|c|c|}
\hline Laboratorio & $\begin{array}{l}6 \text { meses } \\
\text { previos }\end{array}$ & $\begin{array}{l}5 \text { meses } \\
\text { previos }\end{array}$ & 1 visita & $\begin{array}{c}\text { Mes posterior } \\
\text { (centro de referencia) }\end{array}$ & $\begin{array}{l}2 \text { meses } \\
\text { posterior }\end{array}$ \\
\hline Hematocrito (\%) & & 36 & 46 & 42 & \\
\hline Hemoglobina (g/dl) & & 12 & 14 & 14,6 & \\
\hline MCV (fL) & & & & 93,2 & \\
\hline Plaquetas $\left(/ \mathrm{mm}^{3}\right)$ & & 150.000 & 181.000 & 238.000 & \\
\hline Glóbulos blancos $\left(/ \mathrm{mm}^{3}\right)$ & & 19.000 & 15.400 & 13.630 & \\
\hline Neutrófilos/basófilos/eosinófilos/linfocitos/monocitos & & $86 / 0 / 0 / 12 / 12$ & $90 / 0 / 0 / 8 / 2$ & $85 / 0 / 0,8 / 7,15 / 6,88$ & \\
\hline VSG (mm/1 hora) & & 42 & 10 & 20 & \\
\hline PCR (mg/l) & & 34,4 & & & \\
\hline Glucosa (mg/dl) & & 102 & $128\left(^{*}\right)$ & 99 & \\
\hline Urea (mg/dl) & & 33 & 67 & 58 & \\
\hline Creatinina (mg/dl) & & 0,9 & 0,9 & 0,87 & \\
\hline SGOT (IU/I) & & 34 & 18 & 23 & \\
\hline SGPT (IU/I) & & 45 & 23 & 28 & \\
\hline Bilirrubina total (mg/dl) & & & & 1,2 & \\
\hline Fosfatasa alcalina (U/l) & & 151 & 135 & 64 & \\
\hline Colesterol(mg/dl) & & & & 284 & \\
\hline CPK (U/I) & $\left.2466^{(\star *}\right)$ & 62 & & 52 & \\
\hline Aldolasa (U/l) & $\left.10^{(\star \star}\right)$ & & & $8,7(0-7,6)$ & \\
\hline LDH (U/l) & & 518 & & & \\
\hline Tiempo de protrombina (seg) & & 12 & & 13,3 & \\
\hline KPTT (seg) & & & & 40 & \\
\hline Albúmina (g/dl) & & 2,24 & & 3,4 & \\
\hline RIN & & 1 & & 0,98 & \\
\hline Sodio (mEq/L) & & 138 & & 138 & \\
\hline Potasio (mEq/L) & & 4,2 & & 4,9 & \\
\hline Calcio (mg/dl) & & 7,6 & & & \\
\hline Orina & & Normal & & $\begin{array}{l}\text { Proteínas ++ glób. } \\
\text { blancos 5-10 }\end{array}$ & \\
\hline ANA & $1 / 80$ moteado & Negativo & & & $1 / 360$ moteado \\
\hline Anti DNA nativo & & Negativo & & & \\
\hline FR & & Negativo & & & \\
\hline Anti- Ro & & & & & Negativo \\
\hline Anti-La & & & & & Negativo \\
\hline Anti- Sm & & & & & Negativo \\
\hline Anti- RNP & & & & & Negativo \\
\hline ANCA C & & & & & Negativo \\
\hline ANCA P & & & & & Negativo \\
\hline Crioglobulinas & & & & Negativo & \\
\hline C3 (mg/dl) & & & & $75(83-177)$ & \\
\hline $\mathrm{C} 4$ (mg/dl) & & & & $6,8(10-40)$ & \\
\hline $\mathrm{HBs}$ Ag & & & & Negativo & \\
\hline $\mathrm{HBc} a b$ & & & & Negativo & \\
\hline HCV & & & & Negativo & \\
\hline Anticoagulante lúpico & & & & Positivo & \\
\hline Ac-Anticardiolipina lgG & & & & $1 \mathrm{GPL}$ & \\
\hline Ac-Anticardiolipina IgM & & & & 12MPL & \\
\hline Anti-beta2 glicoproteyn I lgG & & & & $1 \mathrm{US}$ & \\
\hline Anti-beta2 glicoproteyn I IgM & & & & $5 U S$ & \\
\hline \multicolumn{6}{|l|}{ Gases en sangre arterial } \\
\hline $\mathrm{HCO3}-(\mathrm{mEq} / \mathrm{L})$ & & 18 & & 25,4 & \\
\hline Pco2 (mmHg) & & 27 & & 37 & \\
\hline $\mathrm{pH}$ & & 7,41 & & 7,45 & \\
\hline Po2 (mmHg) & & 80 & & & \\
\hline
\end{tabular}

Tabla 1. 


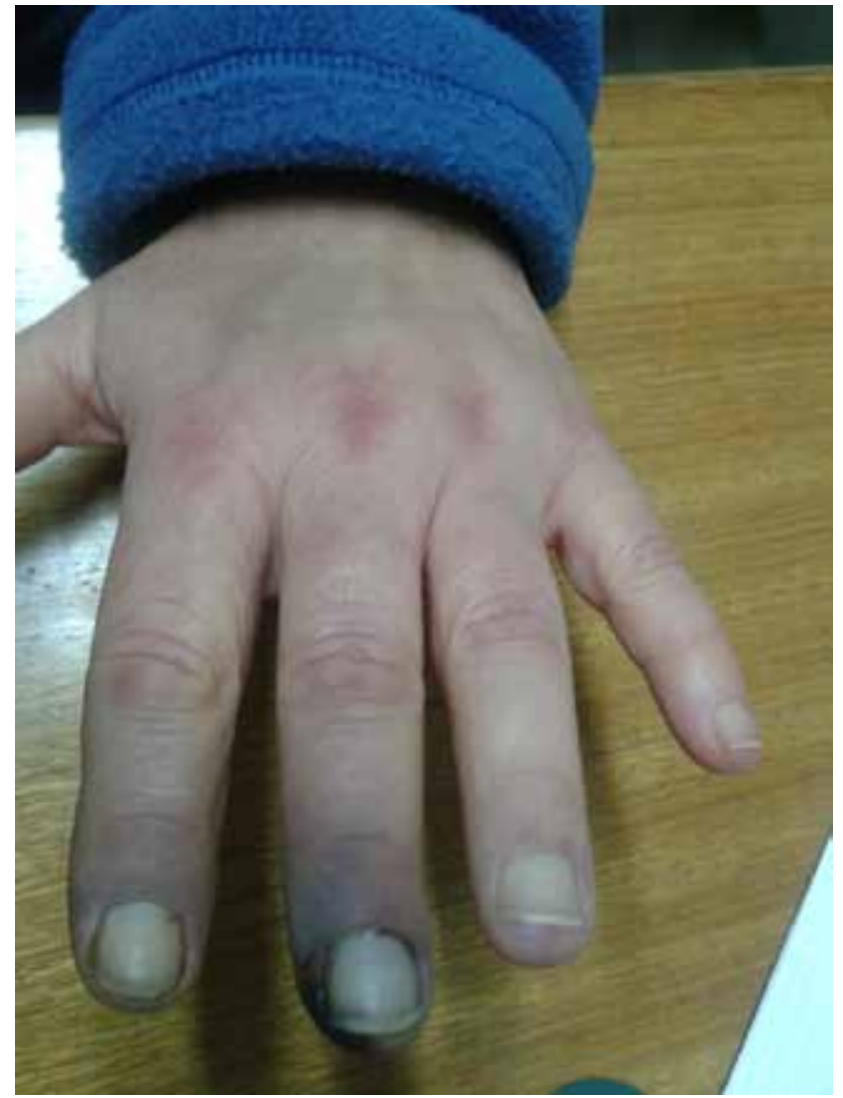

Figura 1.

paciente empeora, presenta necrosis de los demás dedos de ambas manos, presentó proteinuria en el laboratorio, falla multiorgánica (respiratoria, hepática, renal) por lo que se le realiza 5 sesiones de plasmaferesis. En los días subsiguientes evoluciona con mejoría transitoria pero presenta cuadro séptico, como complicación del fallo multiorgánico fallece. Los implantes mamarios fueron removidos durante su internación.

\section{Discusión}

La Dermatomiositis (DM) es una entidad dentro de las miopatías inflamatorias. La incidencia de estas últimas se estima en 1 a 7,3 casos por 1.000 .000 habitantes. Varios alelos HLA están asociados a estas enfermedades autoinmunes. La DM y anticuerpos antisintetasas han sido asociados a los alelos DRB1 y DQA14.

Pocos casos de DM asociados a la presencia de implantes mamarios de silicona han sido reportados en la literatura. Uno de ellos describe el caso de comienzo de la enfermedad seis meses después de la ruptura de una prótesis ${ }^{4}$. En este caso, el signo de Gottron en codos y articulaciones metacarpos falángicos, la debilidad muscular y la elevación de la CPK aparecen meses posteriores a la cirugía. El implante fue removido tarde en su evolución, pero incluso si hubiese sido el desencadenante del cuadro clínico, se desconoce si al ser extraído podría modificar el curso de la enfermedad.

Agentes exógenos, como los compuestos siliconados en este caso, podrían ser un factor desencadenante de una enfermedad autoinmune en un paciente genéticamente predispuesto. Se reporta este caso para considerar esta asociación de eventos, que requerirían ser más observados e investigados.

\section{Bibliografía}

1. 'ASIA' - autoimmune/inflammatory syndrome induced by adjuvants. Shoenfeld Y, Agmon-Levin N. J Autoimmun 2011 Feb; 36(1):4-8.

2. ASIA-autoimmune syndromes induced by adjuvants: rare, but worth considering. Toubi E. Isr Med Assoc J. 2012 Feb; 14(2):121-4.

3. Siliconosis: autoimmune/inflammatory syndrome induced by adjuvants (ASIA). Caldeira M, Ferreira AC. Isr Med Assoc J. 2012 Feb; 14(2):137-8.

4. Pathogenesis and therapies of immune-mediated myopathies. Dalakas MC. Autoimmun Rev. 2012 Jan; 11(3):203-6.

5. A new case of dermatomyositis following the rupture of a silicone gel breast implant. Clin Exp Rheumatol. 2004 May-Jun; 22(3):376. 